\title{
Exploring the Feasibility of Incorporating Sexual Education into Routine Adolescent Office Visits
}

\author{
Holly A. Rankin \\ Nemours duPont Department of Pediatrics, holly.rankin@jefferson.edu \\ Alisa LoSasso, MD \\ Nemours duPont Department of Pediatrics, alisa.losasso@jefferson.edu \\ Beth I. Schwartz, MD \\ Thomas Jefferson University, beth.schwartz@jefferson.edu
}

Follow this and additional works at: https://jdc.jefferson.edu/cwicposters

Part of the Pediatrics Commons

\section{Let us know how access to this document benefits you}

\section{Recommended Citation}

Rankin, Holly A.; LoSasso, MD, Alisa; and Schwartz, MD, Beth I., "Exploring the Feasibility of Incorporating Sexual Education into Routine Adolescent Office Visits" (2016). CWIC Posters. 24.

https://jdc.jefferson.edu/cwicposters/24

This Article is brought to you for free and open access by the Jefferson Digital Commons. The Jefferson Digital Commons is a service of Thomas Jefferson University's Center for Teaching and Learning (CTL). The Commons is a showcase for Jefferson books and journals, peer-reviewed scholarly publications, unique historical collections from the University archives, and teaching tools. The Jefferson Digital Commons allows researchers and interested readers anywhere in the world to learn about and keep up to date with Jefferson scholarship. This article has been accepted for inclusion in CWIC Posters by an authorized administrator of the Jefferson Digital Commons. For more information, please contact: JeffersonDigitalCommons@jefferson.edu. 


\section{Abstract}

Preventative sexual education can reduce the negative health outcomes of sexual behavior in adolescent populations.' The objective of this pilot study was to determine if sexual education can be delivered as a scripted five-minute module during a routine adolescent office vist in a manner that is non-disruptive of clinic flow and acceptable to both patients and providers.

- $85 \%$ of providers reported the intervention did not interrupt clinic flow

- $86 \%$ of patients reported the intervention to be appropriate and $92 \%$ of providers were satisfied overal with the intervention

These pilot data highlight that the incorporation of brief scripted sexual education into routine adolescent preventative office visits is both feasible and acceptable to patients and providers.

\section{Introduction}

The CDC reports around 20 million new cases of sexually transmitted infections (STIs) each year in the United States with around half of these in young people between the ages of 15-24. ${ }^{2}$

As compared to American counterparts, Philadelphia County 10-14 year olds are:

- $5.3 x$ as likely to have Chlamydia

- $4 x$ as likely to have Gonorrhea ${ }^{3}$

Untreated STIs can lead to infertility, ectopic pregnancy, pelvic inflammatory disease, chronic pelvic pain and death

\section{Methods}

Eligible subjects were English-speaking 12-15 year old male and female patients presenting for routine preventative visits at a single urban tertiary care hospital outpatient pediatric practice. Providers included were all practice physicians and nurse practitioners who see patients for routine adolescent preventative visits.

A five-minute scripted sexual education module defining sexual intercourse, associated risks of pregnancy and STIs, ways to reduce risks and recommendations for annual STI screening once sexually active was given by a medical student to eligible patients prior to being seen by a provider in the examination room at the time of a routine physical.

Likert scale surveys assessed baseline provider sexual education counseling, and post-intervention patient and provider thoughts on the intervention's timing and acceptability.

\section{Results}

Fourteen providers completed the pre-intervention survey. All providers reported including sexual education in their routine adolescent preventative office visits and $86 \%$ cited time limitations as a barrier to providing sexual education.

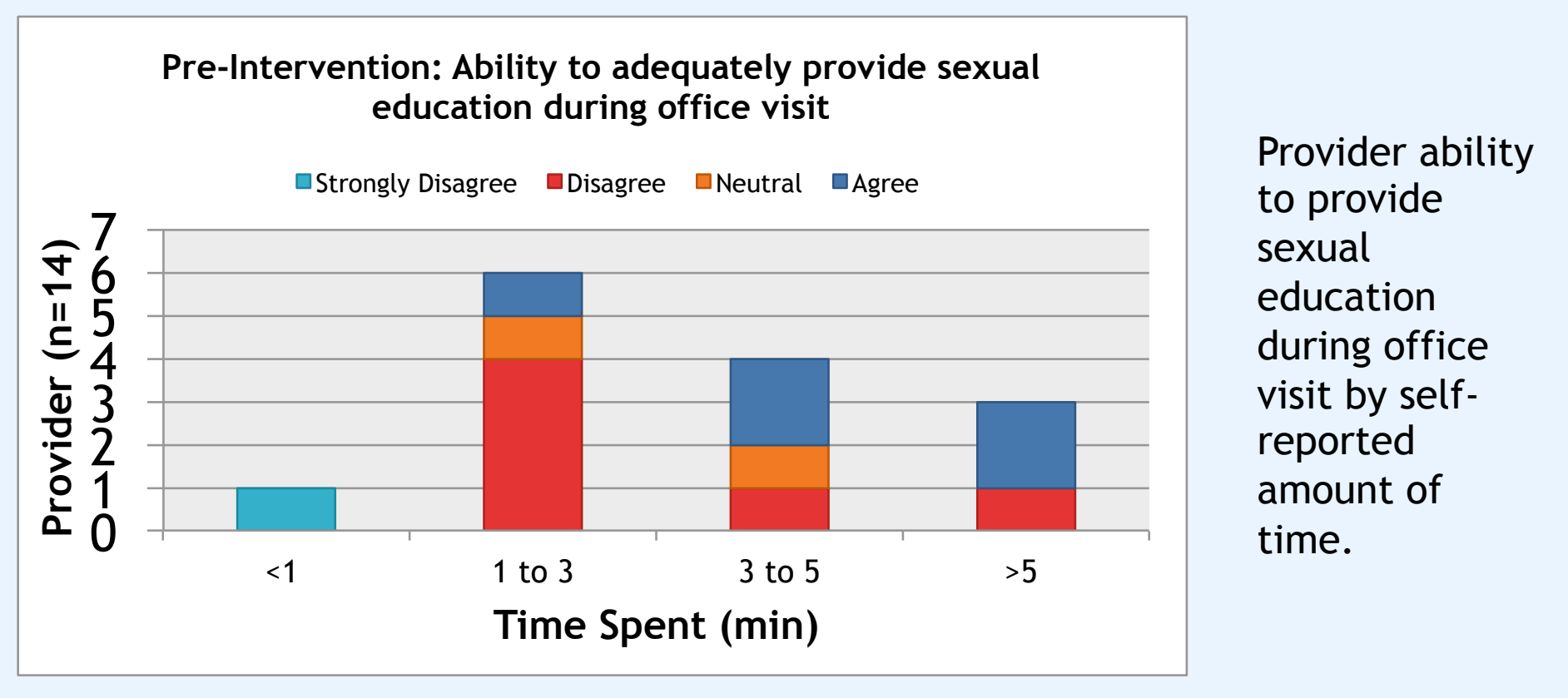

72 eligible patients were approached, 51 (71\%) patients consented to participation and completed the study, and 21 (29\%) patients declined to participate.

\begin{tabular}{|c|c|c|c|}
\hline Characteristic & $\begin{array}{l}\text { Consenting } \\
\mathrm{N}(\%)\end{array}$ & \begin{tabular}{|l|} 
Declining \\
$\mathrm{N}(\%)$
\end{tabular} & $\begin{array}{l}\text { I think it is appropriate to discuss sexual } \\
\text { health education during my doctor's visit. }\end{array}$ \\
\hline \multicolumn{4}{|l|}{ Gender } \\
\hline Male & $23(45)$ & 9 (53) & \\
\hline Female & $28(55)$ & $8(47)$ & \\
\hline \multicolumn{4}{|l|}{ Age } \\
\hline 12 & $6(12)$ & $5(29)$ & \multirow{2}{*}{$\begin{array}{l}\text { I have heard this information from } \\
\text { a doctor before. }\end{array}$} \\
\hline 13 & $11(22)$ & $2(12)$ & \\
\hline 14 & $21(41)$ & $6(35)$ & \\
\hline 15 & $13(25)$ & $4(24)$ & \\
\hline \multicolumn{4}{|l|}{ Race } \\
\hline $\begin{array}{l}\text { Black/African } \\
\text { American }\end{array}$ & $32(62.7)$ & & I learned new information today. \\
\hline White & $11(21.6)$ & & \\
\hline $\begin{array}{l}\text { Asian/Pacific } \\
\text { Islander }\end{array}$ & $3(5.9)$ & & $\begin{array}{l}\approx \text { Disagree } \\
\text { "Neutral }\end{array}$ \\
\hline Other/Mixed & $5(9.8)$ & & - Asree \\
\hline
\end{tabular}

After the intervention period, thirteen of the initially surveyed providers were resurveyed. Eighty-five percent of providers disagreed or strongly disagreed that the intervention interrupted their clinic work flow. Seventy-seven percent of providers agreed or strongly agreed that the intervention was useful and $92 \%$ agreed or strongly agreed to being satisfied with the intervention.

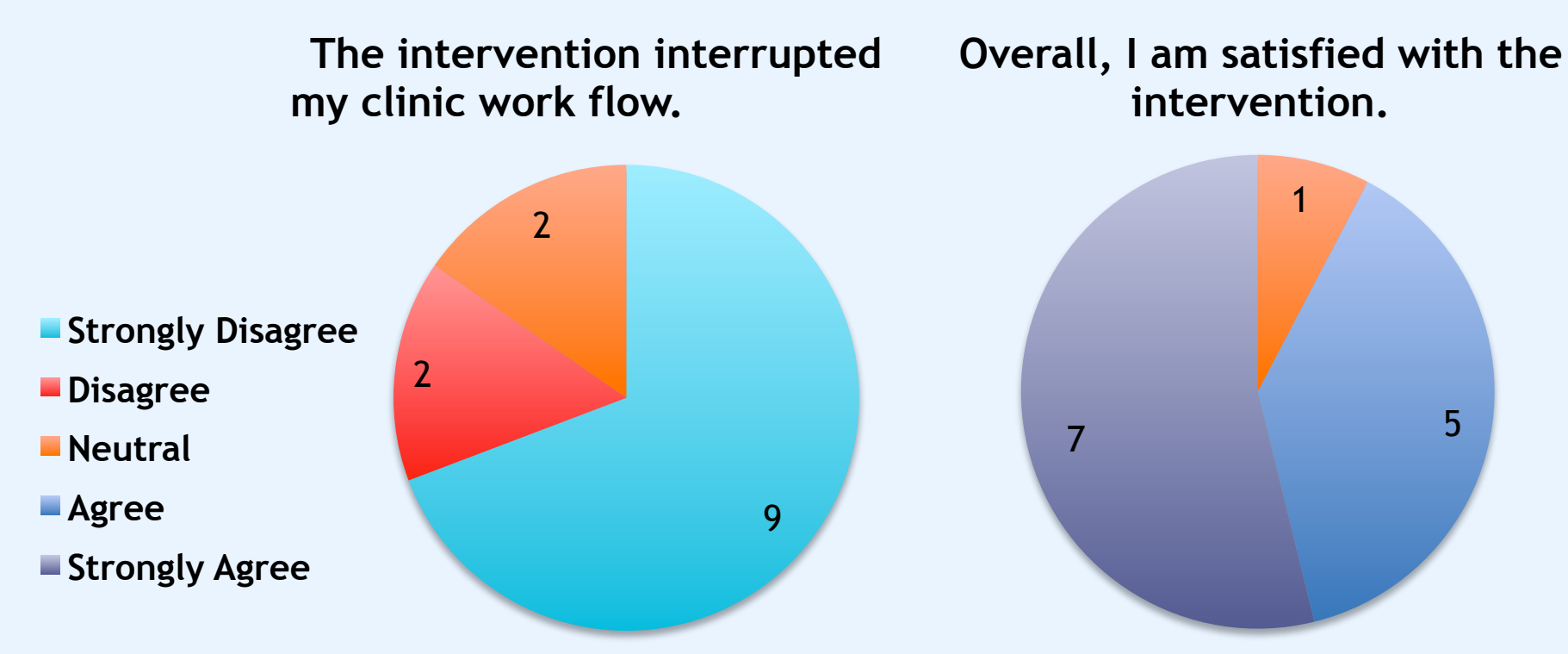

\section{CONCLUSION}

These pilot data suggest that it is feasible to incorporate scripted sexual education into routine preventative office visits in a way that does not interrupt clinic flow and is considered acceptable to patients and providers.

The sexual education all providers reported including in their routine adolescent care was corroborated, with the majority of patients reporting hearing the intervention's information from a provider before. Despite this, the majority of patients also agreed to learning new information from the intervention.

The intervention's timing was well tolerated by providers, with the majority reporting that the intervention did not interrupt clinic flow. In terms of acceptability, the majority of patients felt the intervention to be appropriate and the majority of providers were satisfied with the intervention.

We recommend future incorporation of this module into routine clinical practice and study of the intervention's outcomes on STI testing and STI rates.

\section{REFERENCES}

